\title{
Imaging Geological Structures Up to the Acquisition Surface Using a Hybrid Refraction-Reflection Seismic Method
}

\author{
M. Mendes ${ }^{1 *}$, J.-L. Mari ${ }^{2}$ and M. Hayet ${ }^{3}$ \\ ${ }^{1}$ IST, Dep. of Physics, Lisbon - Portugal \\ 2 IFP Energies nouvelles, IFP school, 1-4 avenue de Bois-Préau, 92852 Rueil-Malmaison Cedex - France \\ ${ }^{3}$ Andra, Centre de Meuse/Haute Marne, 55290 Bure - France \\ e-mail: manuela.mendes@ist.utl.pt - jean-luc.mari@ifpen.fr - michel.hayet@andra.fr \\ * Corresponding author
}

\begin{abstract}
Résumé - Image des structures géologiques des profondeurs à la surface, grâce à une méthode de sismique hybride entre la réflexion et la réfraction - Le but de l'imagerie sismique est de reconstruire la réflectivité associée aux structures superficielles. Cependant, lors des reconstructions classiques, le modèle de réflectivité commence en général quelques mètres sous la surface, en fonction du mute utilisé pour supprimer les artéfacts liés aux arrivées premières et aux paramètres d'acquisition. Pour pallier ceci, nous utilisons dans cet article une approche pour imager la réflectivité des surfaces peu profondes dès la surface. Cela est réalisé en traitant les arrivées premières et les phases réfléchies dans les données de la réfraction. La procédure d'imagerie proposée se déroule en trois étapes. Premièrement, nous obtenons le modèle de vitesse pour la partie supérieure à partir de la méthode plus/minus et de l'inversion tomographique des arrivées premières ; deuxièmement, en traitant les évènements réfléchis, présents dans les données de réfraction, on obtient une section de réflectivité standard pour les zones plus profondes; et, enfin, nous calculons la prolongation de la réflectivité pour la partie supérieure grâce au modèle de vitesse fourni par l'inversion tomographique en premier lieu. Le modèle de vitesse est utilisé pour calculer la distribution de réflectivité et pour la conversion en profondeur des sections en temps. La réflectivité ainsi obtenue est associée aux contrastes de vitesse. Afin de le faire coïncider avec la distribution de réflectivité associée aux contrastes d'impédance, un facteur d'échelle entre les deux jeux de distribution de réflectivité doit être calculé.

La nouveauté de cette contribution est l'emploi d'un modèle de vitesse dans l'évaluation de la réflectivité pour la partie supérieure de la section, ce qui améliore l'information continue sur l'ensemble des structures superficielles en comparaison avec les travaux antérieurs limités aux données de la réflexion.

Trois exemples de terrain illustrent la méthode proposée en montrant la continuité de l'information sur la réflectivité des structures dès la surface.
\end{abstract}

Abstract - Imaging Geological Structures Up to the Acquisition Surface Using a Hybrid Refraction-Reflection Seismic Method - The aim of seismic imaging is to reconstruct the reflectivity associated with subsurface structures. In standard imaging techniques, the reflectivity model usually starts a few meters below the surface, the actual depth being dependent on data acquisition 


\begin{abstract}
parameters and the mute used to remove stretching of first arrivals after normal moveout correction. In this paper, we describe a method to image the reflectivity of near-surface structures starting from the acquisition surface. This is achieved by processing both the first arrivals and the reflected phases present in data collected for refraction surveys. The proposed imaging procedure works in three steps. First, we obtain a velocity model for the shallow region by combining the Plus-Minus method of refraction interpretation with tomographic inversion of first arrival times. Second, by processing reflection events present in the refraction data, we obtain a standard reflectivity section for the deeper region. Finally, we compute reflectivity for the shallow region using the velocity model estimated from first arrival information in step 1. This velocity model is used both to compute reflectivity and to convert it in time. The reflectivity obtained for the shallow region is associated with velocity contrasts. In order to merge it with the reflectivity section for the deeper region a scaling factor between the two sets of reflectivity sections must be computed and applied.

The novelty of this contribution is the use the tomographic velocity model in evaluating reflectivity for the upper part of the section. This improves the continuity of information about all near-surface structures in comparison with previous works that were limited to reflection data.

Three field examples illustrate the proposed procedure showing continuous information about reflectivity of structures starting from the acquisition surface.
\end{abstract}

\section{INTRODUCTION}

The seismic refraction method has been used extensively to determine depth-to-bedrock or depth to other seismic velocity boundaries (Palmer, 1986; Sain and Kaila, 1996; Zelt et al., 2006). More recently, the seismic refraction method has been increasingly used in shallow environmental and engineering site characterisation studies (Redpath, 1973; Nayan et al., 2003; Wongpornchai et al., 2009, Mari and Delay, 2011). In both cases, subsurface information is derived from first-arrival times rather than reflection events that are also present in refraction data.

Typically, with refraction analysis of first arrival travel times, the depth of investigation is limited to approximately $1 / 3$ the length of the active receiver spread. On the other hand, the processing and interpretation of reflection events present in the refraction data allows the depth of investigation to increase to approximately the length of the spread. Also the acquisition of highquality shallow reflection seismic data requires higher spatial sampling than co-located refraction data and the processing of shallow reflection seismic data requires careful attention to statics corrections, velocity estimation, and noise attenuation.

To deal with these limitations inherent in the refraction and reflection methods, we develop an innovative procedure to integrate the analysis of both the refracted and the reflected waves present in data collected for refraction surveys and derive the reflectivity associated with near surface geological structures. In particular, we utilize first-arrival times to construct a near-surface velocity model by combining the conventional PlusMinus method of refraction interpretation with tomographic inversion (Mari and Mendes, 2012). Then, we perform seismic reflection processing of the data recorded for the refraction survey in order to obtain a single-fold, high-resolution seismic section for the deeper part. The final seismic section is inverted for acoustic impedance, and the acoustic impedance section is then converted to reflectivity. Finally, the near-surface $P$ wave velocity model computed by the travel time tomography is used to extend the reflectivity section obtained in step 2 upward in time to the acquisition surface. The purpose of the current work is to take advantage of the $P$-wave velocity model derived from travel time tomography to extend the reflectivity section upward in time from the early mute time of the reflection profile obtained in step 2 to time zero.

In summary, we present a relatively simple processing procedure to provide knowledge about the reflectivity of the subsurface using a fast and inexpensive 3 step method: 1. $P$-wave velocity estimation for the very near surface using the Plus-Minus method and tomographic inversion of first arrival times;

2. processing of reflection energy in the refraction data to obtain a $P$-wave reflectivity section for deeper region;

3. upward continuation of $P$-wave reflectivity from that obtained in step 2 using the $P$-wave velocity model obtained in step 1.

Three field examples show the efficiency of the proposed procedure to provide continuous reflectivity information starting from the acquisition surface.

\section{IMAGING PROCEDURE}

Our goal is to introduce a new procedure for estimating reflectivity in shallow-target geophysics. We adopted an 
approach based on the three steps described in the introduction. Each step will be described in detail below.

The first step involves the tomographic inversion of first arrival data. Our inversion strategy, developed by Mendes (2009), is based on a Simultaneous Iterative Reconstruction Technique (SIRT), and to be successful, requires a priori knowledge of the background velocity to build a well suited initial model. The requirement of an initial velocity model that is, by some measure, close to the final velocity model, allows the inversion algorithm to avoid entrapment in local minima and ensures good convergence for the optimization method. We choose the conventional Plus-Minus method (Hagedoorn, 1959) to produce this initial model since it offers a good evaluation of the refractor velocity analyses and can be optimized when shot spacing is sparse in constrained field conditions (Whiteley and Eccleston, 2006). The optimization scheme used in the tomographic inversion aims to minimize a misfit function, which is defined as the least-square error between computed and picked first break times, by adjusting the values of the velocity model. The velocity model, defined on a grid with a constant velocity value in each cell, is updated until the value of the misfit function reaches a threshold that is defined by the modeller. To compute the travel times, we use a finite difference method developed by Podvin and Lecomte (1991) to solve the eikonal equation through an application of Huygens's principle. We then estimate the energy paths for each source-receiver ray using the first Fresnel volume approach presented by Cerveny and Soares (1992). The Root-Mean-Square (RMS) deviation between calculated and observed first-arrival times is used to evaluate the effectiveness of the inversion. This inversion technique gives an estimate of the velocity distribution in the upper low velocity zone (weathering zone).

The second step uses seismic phases recorded in a standard refraction survey to obtain a reflectivity section. A refraction profile is commonly composed of 2 or 3 shot points recorded on the same geophone line: 2 end-on spread shots and one split spread shot if 3 shots are recorded. The reflection data in these shots can be processed to obtain a low-fold reflection profile. The processing of reflected events in low-fold reflection profiles requires particular attention to the attenuation the coherent noise. In particular, the presence of surface waves - predominantly Rayleigh and Love waves - in the time and offset range of interest complicates the processing of reflected waves (Yilmaz, 1987, Mari et al., 1999). The processing must to be able to separate weak reflected events from high-energy surface waves. Wave separation is therefore a crucial step in the processing sequence. We show the benefit of combining two different wave-separation methods in order to attenuate high-energy source generated noise. The conventional F-K method is used to filter surface waves and converted refracted waves. The Singular Value Decomposition (SVD) method (Mari et al., 1999) is used to extract refracted waves. The complete processing sequence for each individual shot point is as follows:

- amplitude recovery,

- deconvolution by spectrum equalization,

- wave separation by SVD and F-K filters,

- static corrections based on the velocity model obtained by the tomographic inversion,

- velocity analysis by velocity scan,

- Normal Move-Out (NMO) corrections.

The NMO-corrected shot points are sorted to common reflection point position in order to obtain a single fold reflectivity section RZ. The reflectivity section displays the reflection coefficients associated with subsurface structures, filtered in the seismic frequency bandwidth. At normal incidence, the reflectivity becomes:

$$
R Z_{i}=\left(Z_{i+1}-Z_{i}\right) /\left(Z_{i+1}+Z_{i}\right)
$$

where $Z_{i}$ is the acoustic impedance (product of the density and velocity) at cell $i$ and $Z_{i+1}$ is the acoustic impedance at cell $i+1$.

The third step is the upward continuation of the reflectivity section obtained by step 2 using the velocity model provided by travel time tomography. The velocity model is used to compute a reflectivity section $R V$, using the following definition for reflectivity:

$$
R V_{i}=\left(V_{i+1}-V_{i}\right) /\left(V_{i+1}+V_{i}\right)
$$

where $V_{i}$ is the velocity at cell $i$ and $V_{i+1}$ is the velocity at cell $i+1$. We do not take into account the density to compute the reflectivity coefficient. The velocity model is also used to convert in time the reflectivity associated with velocity contrasts which is then filtered in the frequency bandwidth defined in the second processing step. In order to merge the reflectivity section derived from the velocity model in step 1 with the reflectivity section derived from acoustic impedance contrasts in step 2, a scaling factor between the two sets of reflectivity distribution ( $R V$ and $R Z$ ) must be computed in order to match the amplitudes of the two sections. The scaling factor $k$ is defined as follows:

$$
R Z=k \cdot R V
$$

The scaling factor is computed from the amplitude ratio of the 2 reflectivity sections in a time - distance window where the reflected wave on the bottom of 


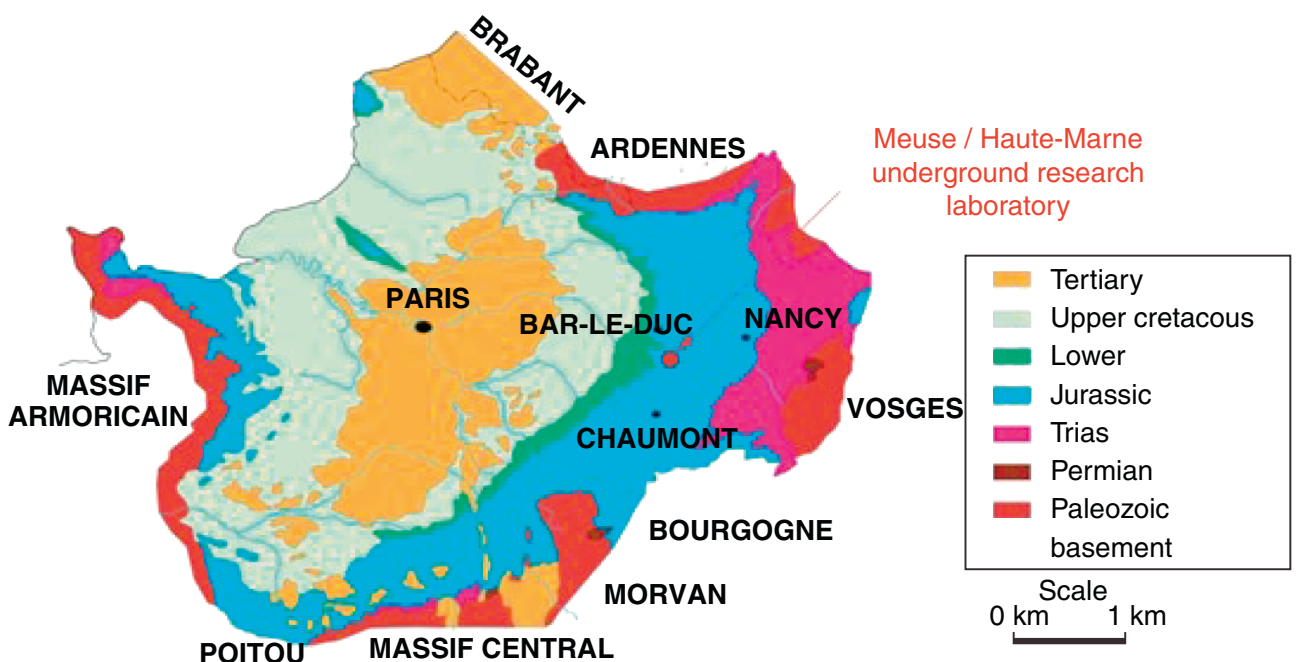

a)

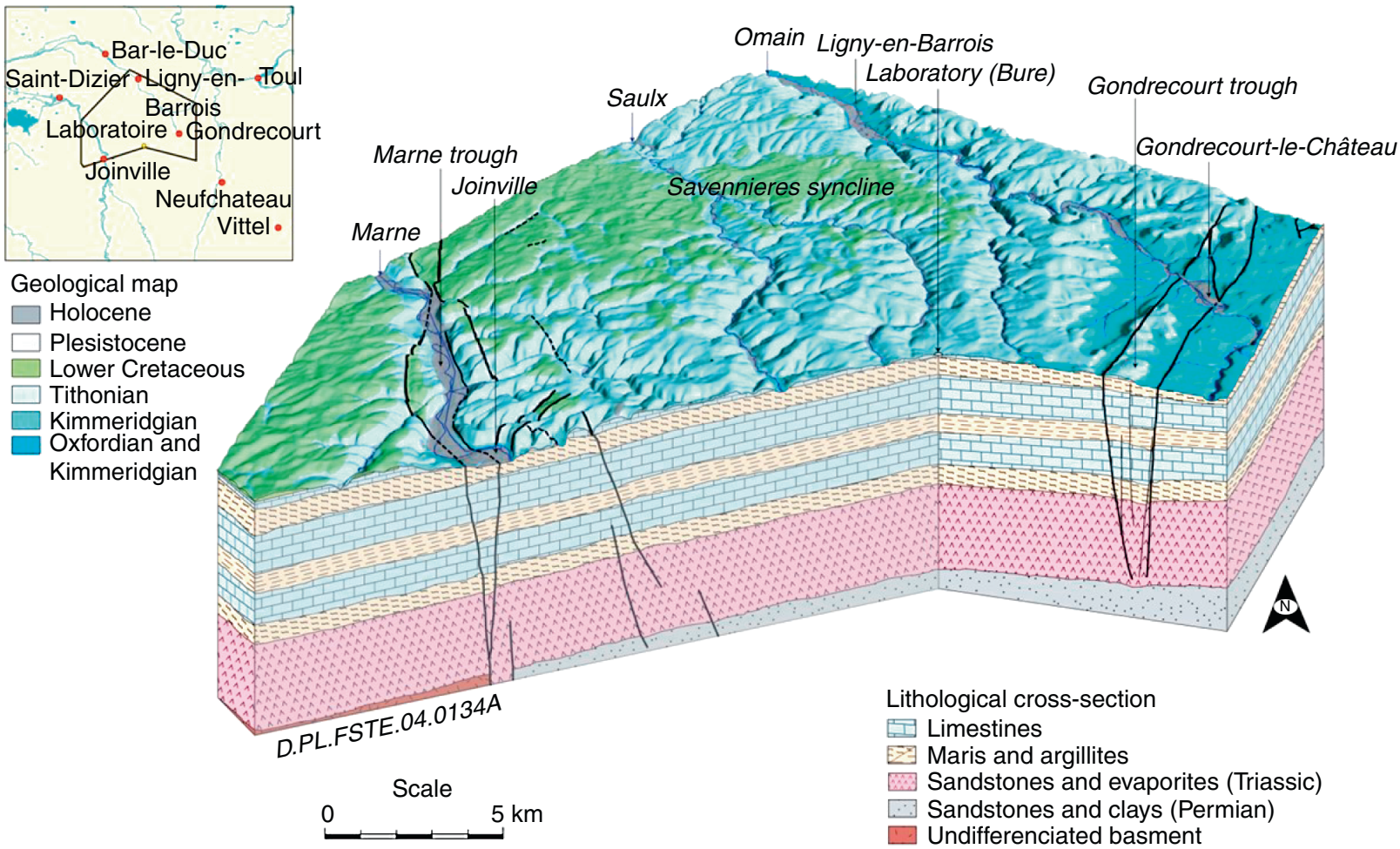

Relif magnification: $x 4$

b)

Figure 1

Geological map. a) Simplified geological map of the Paris Basin showing the location of the Andra underground research laboratory; b) a detailed $3 \mathrm{D}$ cross-section of the target region relief and lithology. (Courtesy of Andra) 
the weathering zone is seen. In practice, the timedistance window is defined as follows: time window (between $0.025 \mathrm{~s}$ and $0.050 \mathrm{~s}$ ) for the short offsets (between $0 \mathrm{~m}$ and $25 \mathrm{~m}$ ).

With field examples, we show the benefit of processing shot points recorded for refraction surveys in order to provide continuous reflectivity information starting from the ground surface.

\section{FIELD EXAMPLES}

The dataset comes from a High Resolution 3D seismic survey recorded in France at the boundary of the Meuse and Haute-Marne departments in the vicinity of the Andra (National radioactive waste management Agency) Laboratory.

\subsection{Geology Setting}

The Meuse/Haute-Marne sector is located in the eastern part of the Paris Basin (Fig. la). The sedimentary succession shows a simple, monocline structure, dipping towards the centre of the basin (NW) which follows the general structure of the basin.
More than 2 thousands meters of Mesozoic formations have been encountered in a well in the Meuse/ Haute-Marne sector (Fig. 1b) with more than seven hundred meters of Triassic deposits, about three hundred meters of Liassic formations and more than nine hundred meters of middle and upper Jurassic deposits.

\subsection{Seismic Survey}

The 3D survey covers an area of $37 \mathrm{~km}^{2}$ (magenta polygon in Fig. 2). The 3D design is a cross spread. The active spread is composed of 12 receiver lines with 120 stations each. The source lines are perpendicular to the receiver lines. The receiver and source line spacing is $80 \mathrm{~m}$ and $120 \mathrm{~m}$ respectively. The receiver and source point spacing is $20 \mathrm{~m}$. The source consisted of a single vibrator sweeping from 14-140 Hz. The sweep time was $10 \mathrm{~s}$ and the listen time was $12 \mathrm{~s}$. The bin size is $10 \times 10 \mathrm{~m}^{2}$. The nominal fold is 60 . The area associated with the nominal fold is restricted to an area of $28.5 \mathrm{~km}^{2}$ (red polygon in Fig. 2). A conventional seismic sequence was applied to the acquired data set. It includes amplitude recovery, deconvolution and wave separation, static corrections, velocity analysis and pre-stack time migration.

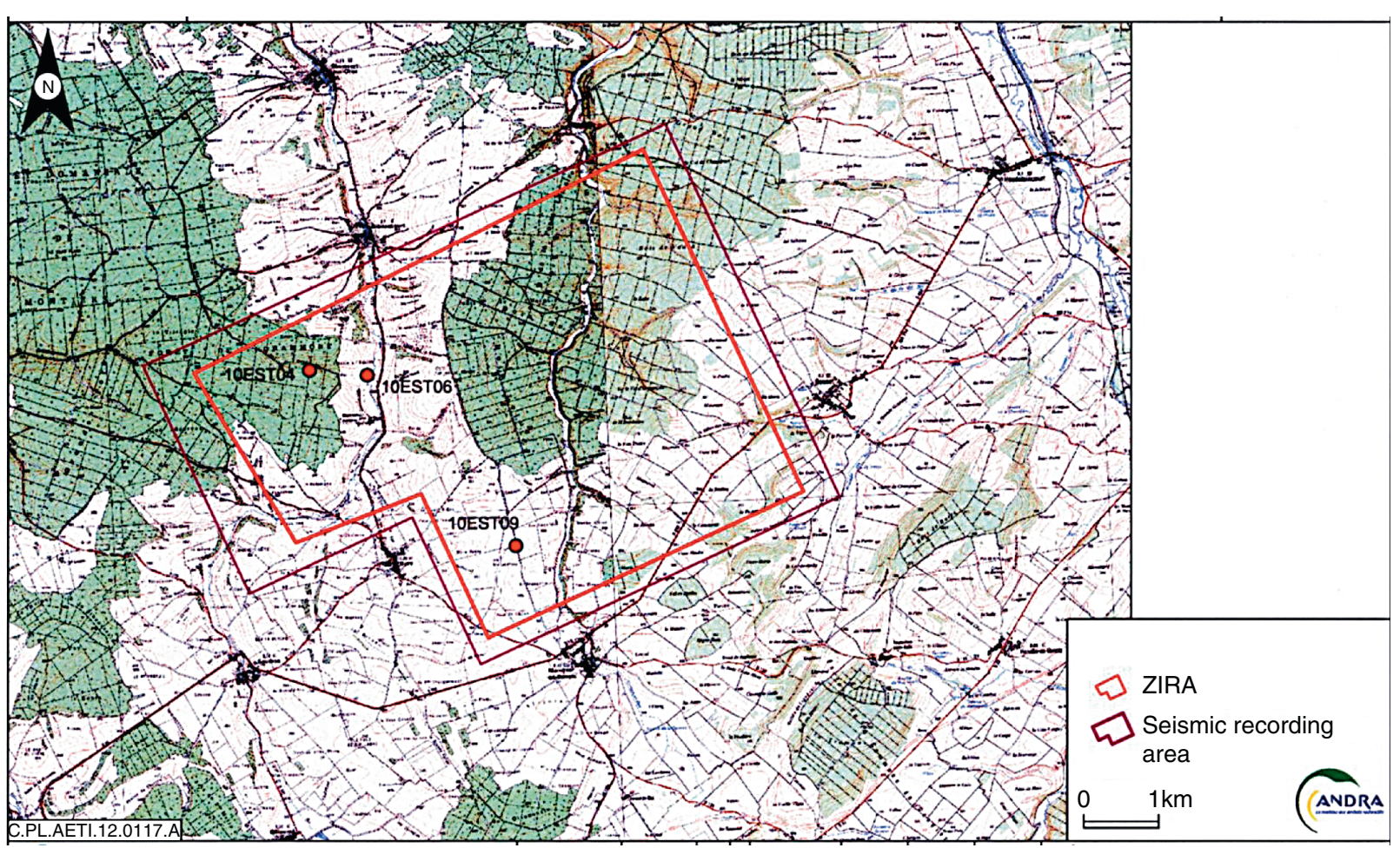

Figure 2

Area of the 3D seismic reflection survey (magenta polygon) and location of 3 relevant 2D seismic refraction profiles (red points): 10EST04, 10EST09, 10EST06. (Courtesy of Andra) 

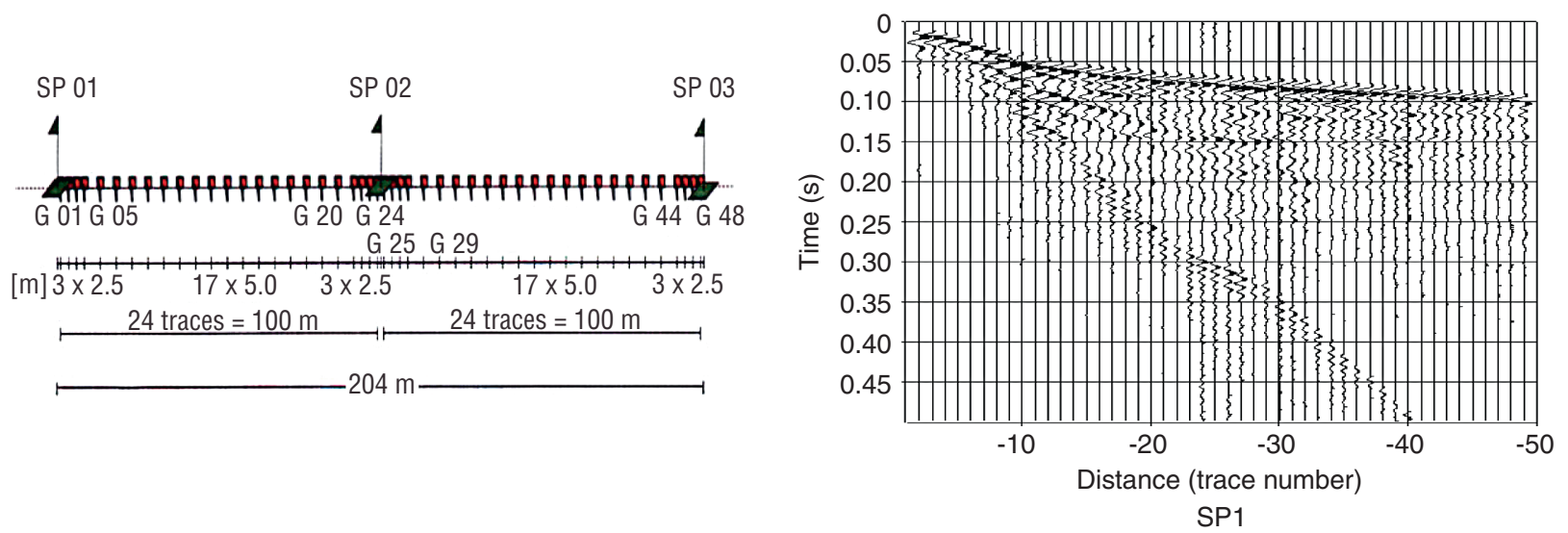

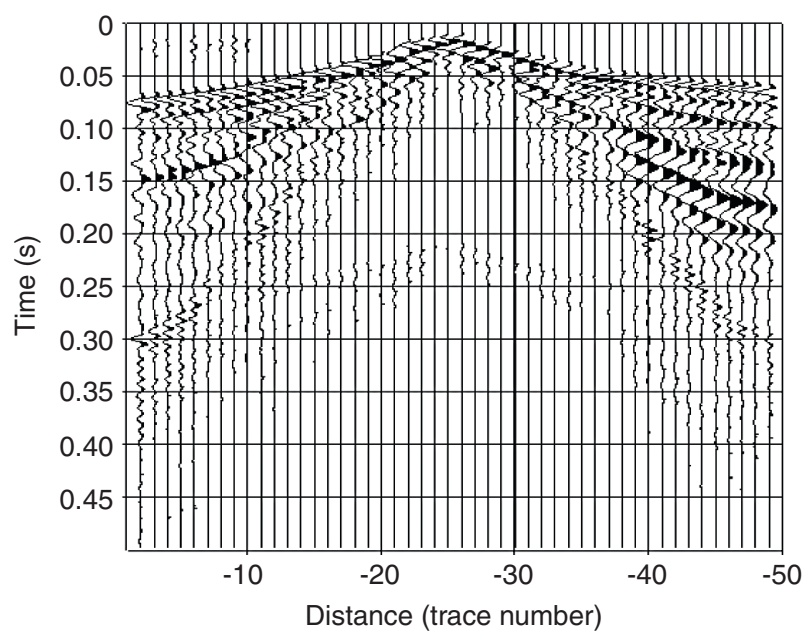

SP2

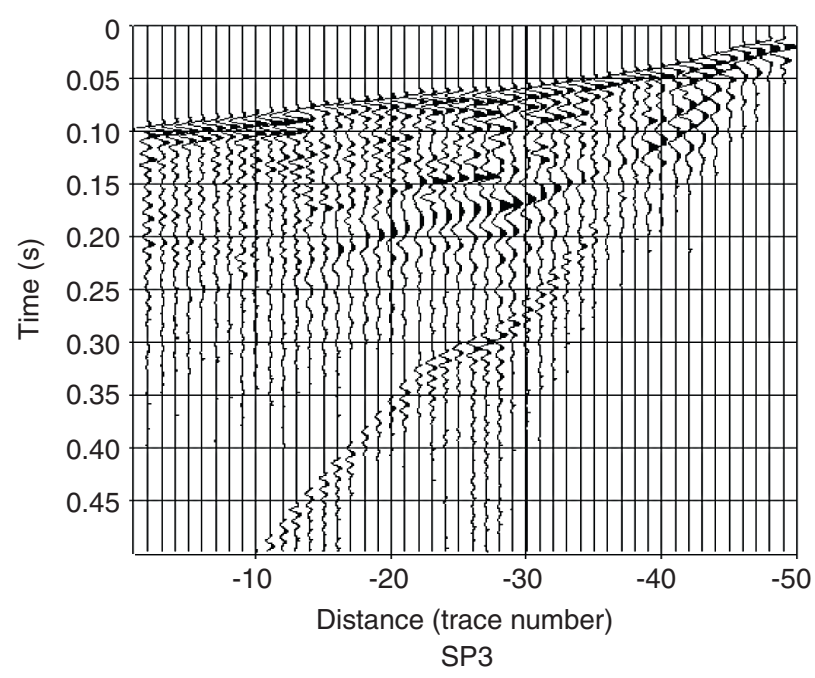

Figure 3

Refraction seismic acquisition: spread and examples of shot points for the 10EST04 profile.

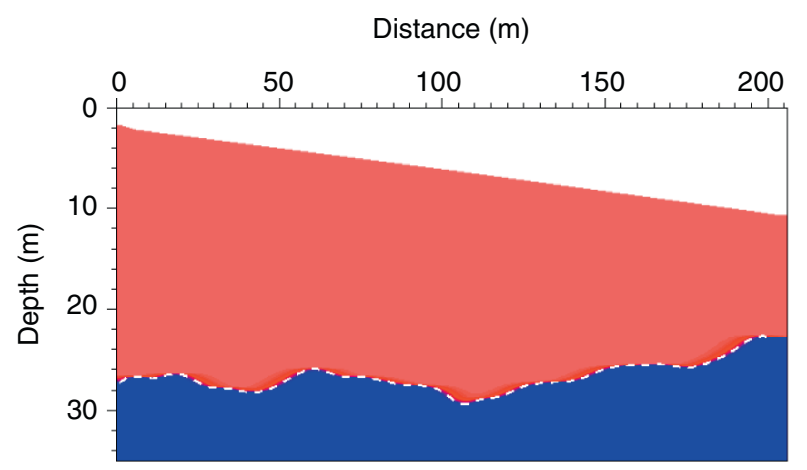

a)

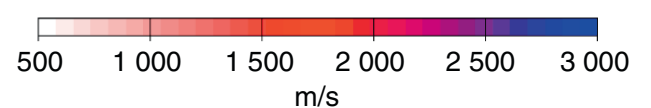

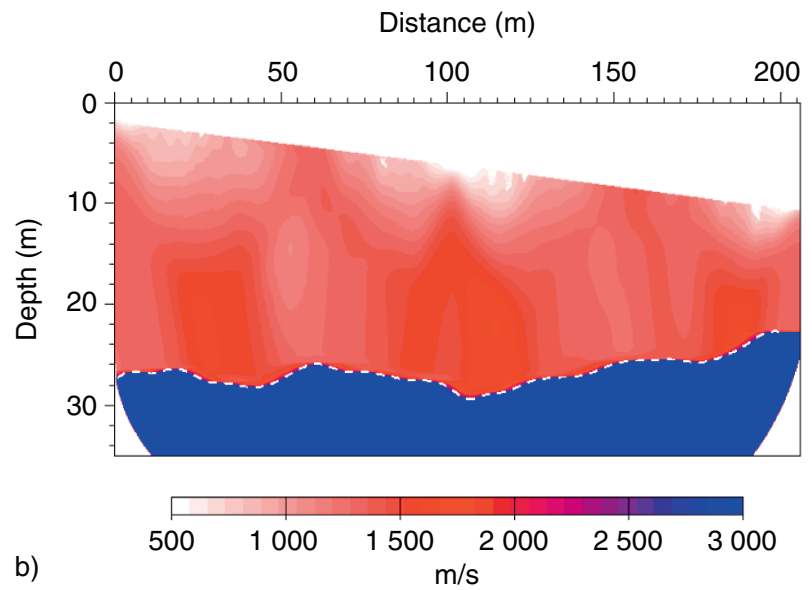

Figure 4

Tomographic inversion for the 10EST04 profile: a) input model $V 1=1300 \mathrm{~m} / \mathrm{s}$ and $V 2=3250 \mathrm{~m} / \mathrm{s}$; b) result of the tomographic inversion. 

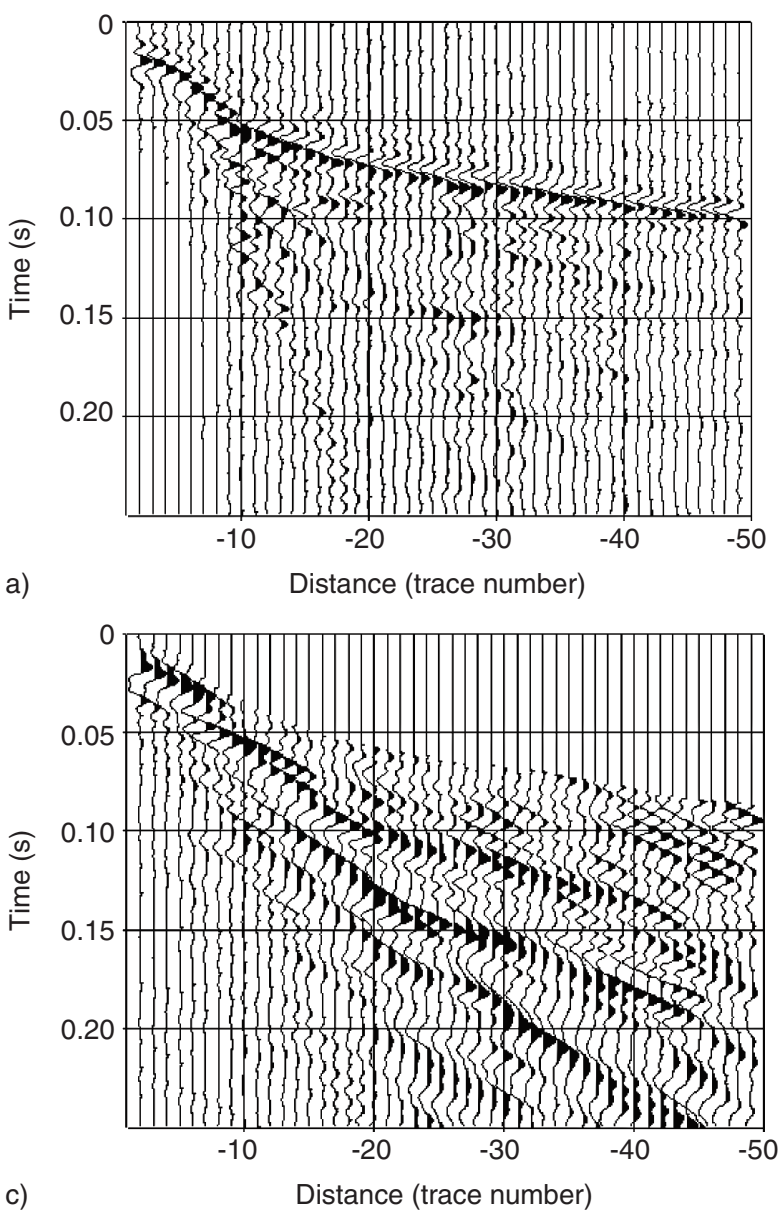
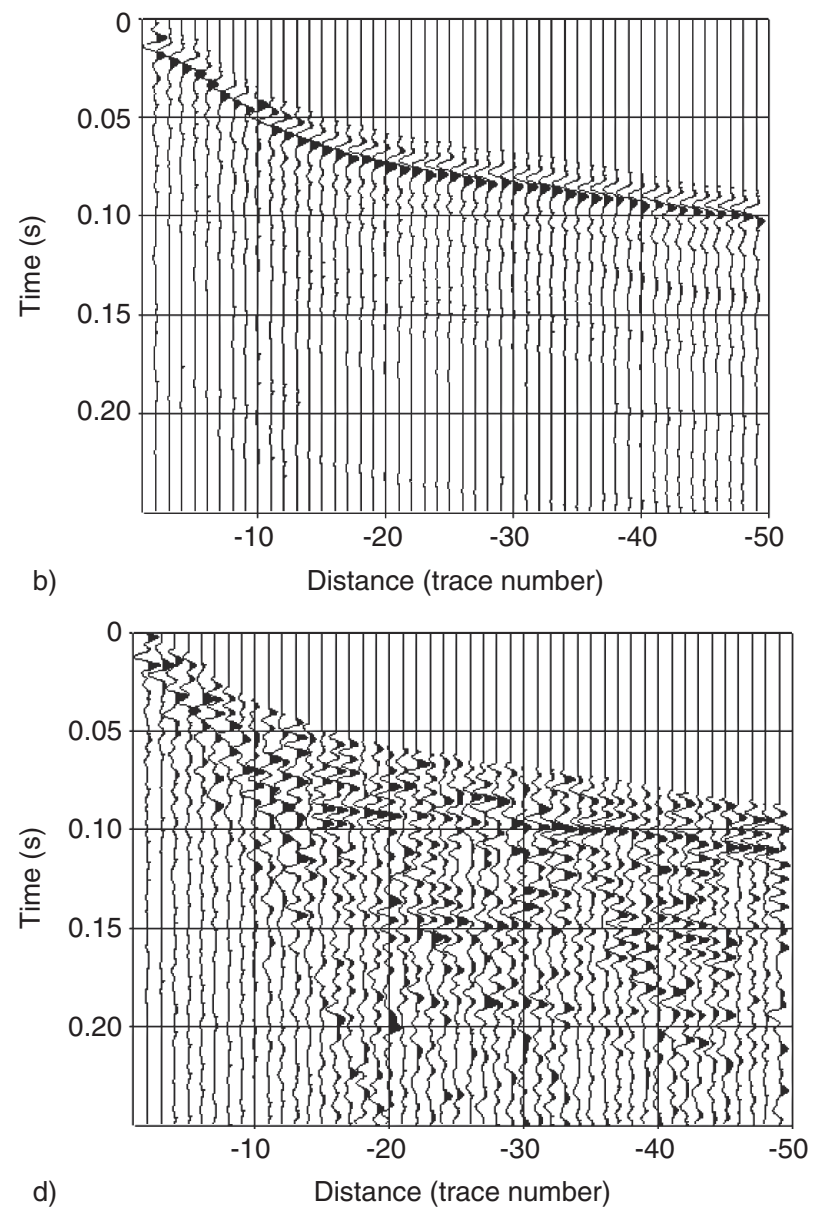

Figure 5

Deconvolution and wave separation for the 10EST04 profile: a) deconvolution; b) direct and refracted waves (SVD filter); c) pseudoRayleigh waves (F-K filter); d) reflected waves and residual noise.

In addition to the main $3 \mathrm{D}$ survey, $30 \mathrm{~km}$ of $2 \mathrm{D}$ refraction profiles were acquired by $D M T G m b H \&$ Co. $K G$ with the aim of providing detailed statics information for the $3 \mathrm{D}$ reflection survey. Each individual profile consisted of 3 shot points recorded by a fixed spread of 48 in-line geophones laid out over a distance of $202 \mathrm{~m}$ (Fig. 3): shot point 1 was located $1 \mathrm{~m}$ off-end from geophone 1 , shot point 2 was located in the center of the spread, equidistant to geophones 24 and 25, and shot point 3 was located $1 \mathrm{~m}$ off-end from geophone 48 . The distance between adjacent geophones is $2.5 \mathrm{~m}$ for geophones 1-4, 21-24, 25-28 and 45-48. The distance between geophones 4 to 21 and geophones 28 to 45 is $5.0 \mathrm{~m}$. The distance between geophones 24 and 25 is $2.0 \mathrm{~m}$. Source-receiver offsets range from 1.0 to $203.0 \mathrm{~m}$ for source points 1 and 3 , and from 1.0 to $101.0 \mathrm{~m}$ for source point 2 . The seismic source is a weight dropper $(10 \mathrm{~kJ})$. The receivers are $10 \mathrm{~Hz}$ vertical geophones.

Andra has selected three profiles to review our proposed imaging procedure. Figure 2 shows the location of the three profiles (red points).

\subsection{Imaging Using Refracted Data}

We describe in detail the different steps of the seismic processing procedure for the 10EST04 profile. Figure 3 shows the acquisition spread and the shot points recorded with the spread.

\subsubsection{First Processing Step: Tomographic Inversion}

Based on the first-arrival times the Plus-Minus method produced an estimate of the refractor velocity (V2) and 

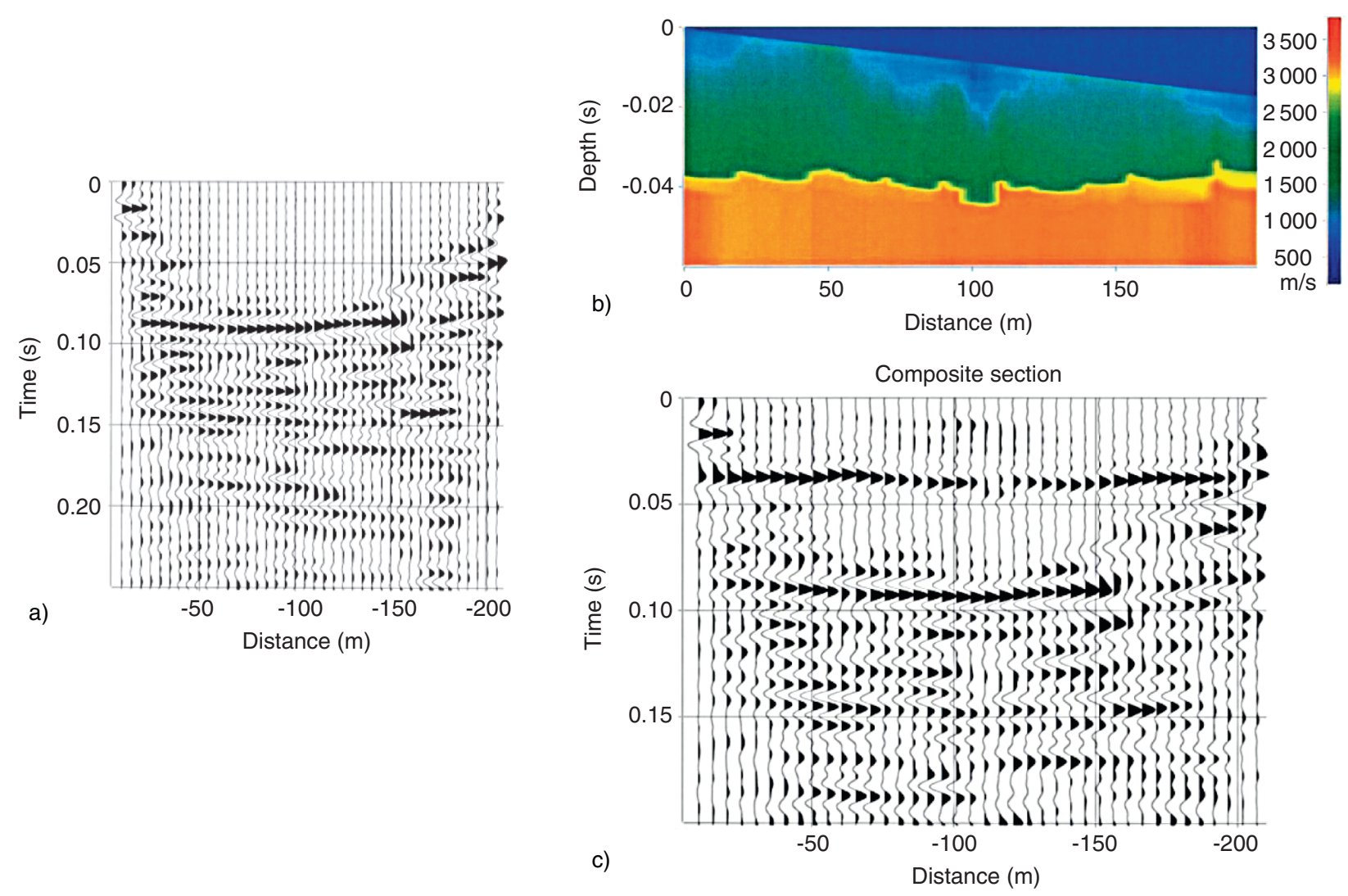

Figure 6

Reflectivity section for 10EST04 profile: a) single fold section derived from reflection processing of end-on shots; b) time converted velocity model obtained by tomographic inversion; c) upward continuation of single-fold section using reflectivity derived from tomographic velocity model.

the depth of the refractor. Analysing the slope of the travel time-distance plot for the direct wave, a linear behaviour was found, suggesting a constant velocity for the first layer. Collecting all the information available, we built the initial model with 2 layers. The velocity of the first layer was determined using a series of constant velocity distributions and the second layer with constant velocity provided by the $T$ minus curve (Fig. $4 a$ ). We use the tomographic inversion to select the optimum model in the sense of the misfit function minimization. This input model is a single layer with a constant velocity $(V 1=1300 \mathrm{~m} / \mathrm{s})$ over a bedrock with a velocity of $V 2$ $=3250 \mathrm{~m} / \mathrm{s}$. The velocity model, defined on a grid with $0.1 \times 0.1 \mathrm{~m}$ and a constant velocity value in each cell, is updated until the value of the misfit function reaches a threshold that is defined by the modeller. The image presented in Figure $4 \mathrm{~b}$ corresponds to the tomographic inversion result, stopped after 16 iterations, when the RMS deviation between calculated and observed first-arrival times is only $0.5 \mathrm{~ms}$. The comparison between the initial and the final model shows strong lateral variations of velocity in the weathering zone.

\subsubsection{Second Processing Step: Seismic Imaging with Reflected Waves}

We have processed off-end shots 1 and 3 in order to obtain a single-fold section. The processing sequence includes amplitude recovery, spectrum equalization from 12-160 Hz, wave separation by SVD and F-K filters, static and velocity corrections. Figure 5 shows the steps concerning the deconvolution and the wave separation for the shot point 1 .

The complete wave-separation procedure used to attenuate coherent noise is performed on shot records in two parts. In the first part, direct and refracted waves are removed using a SVD filter. To optimize the procedure, the direct and refracted arrivals are 

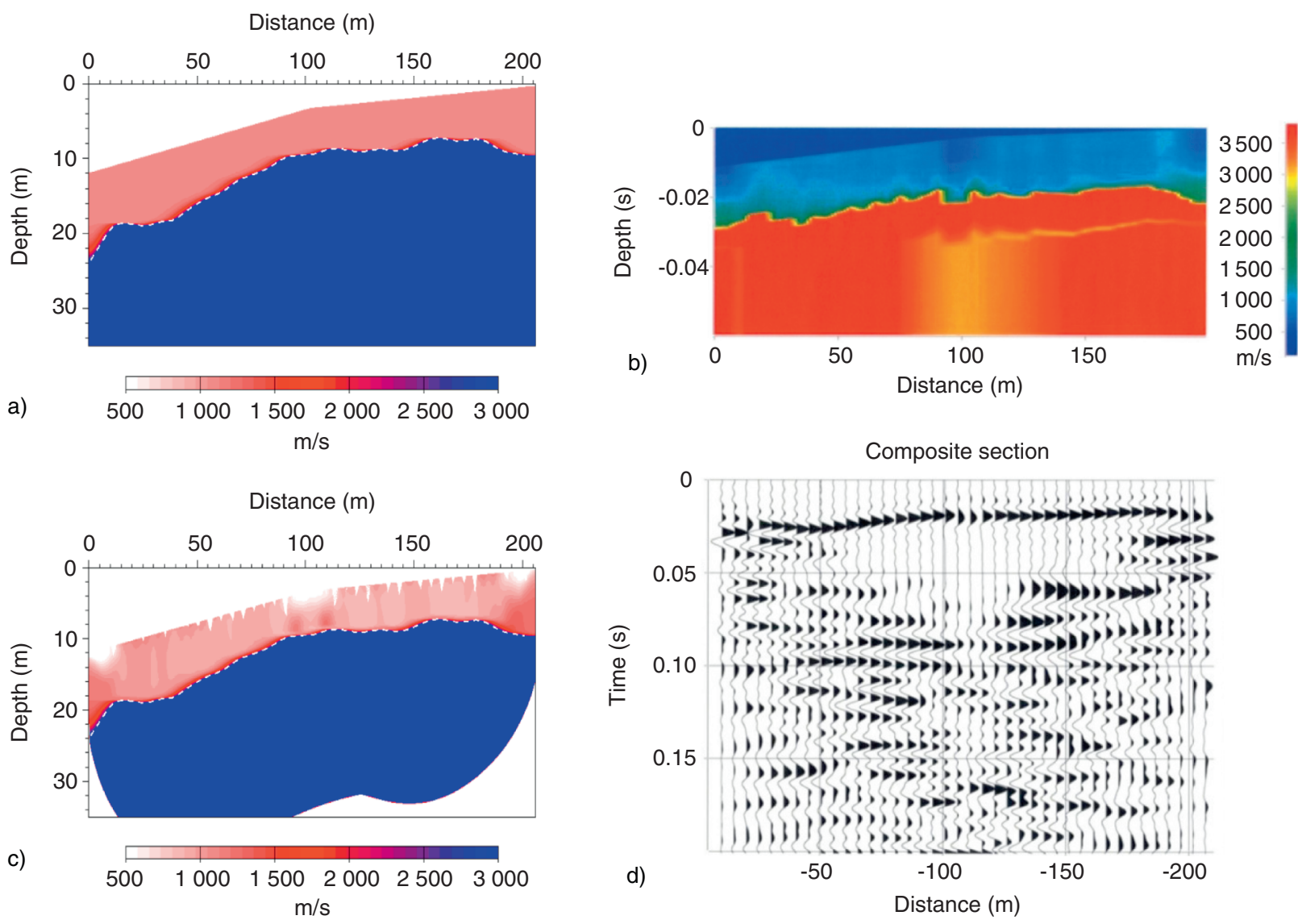

Figure 7

Second field example: reflectivity section for 10 EST09 profile. a) Velocity model derived by the Plus-Minus method $(V 1=1087 \mathrm{~m} / \mathrm{s}$ and $V 2=3975 \mathrm{~m} / \mathrm{s}$ ). b) Velocity model from tomographic inversion after conversion depth to time. c) Velocity model derived by tomographic inversion. d) Composite reflectivity section.

flattened prior to SVD so that they have infinite apparent velocity. The time-shifts used to flatten these events are obtained from the first arrival times picked for refraction analysis. These time-shifts are removed after SVD to return the data to their initial position. The first two eigen sections obtained by SVD of the flattened record are used to reconstruct a model of the direct and refracted waves (Fig. 5b). This model is subtracted from the input shot record to obtain a residual record in which the direct and refracted arrivals have been greatly attenuated.

In the second step, pseudo-Rayleigh surface waves (low apparent velocity waves) are removed from the residual record using a F-K filter. Similar to the SVD filtering procedure, the F-K filter is used to extract a model of the low velocity waves (Fig. 5c). The model is subtracted from the residual record obtained from SVD filtering to obtain a final residual record that clearly shows high apparent velocity events that are associated with reflected waves (Fig. 5d).

The processing sequence leads to a very high-resolution reflectivity section displayed in amplitude, which shows seismic horizons down to $200 \mathrm{~ms}$ (Fig. 6a).

\subsubsection{Third Processing Step: Upward Continuation of the Reflectivity Section}

The velocity model estimated by tomographic inversion of first arrival times was converted to time (Fig. $6 b$ ) and transformed to reflectivity (Fig. 6c). This reflectivity section is then used to extend the reflectivity section obtained from the single fold seismic. The final result of the three-step procedure is a composite reflectivity section (Fig. 6a). The main reflection above at approximately $40 \mathrm{~ms}$ is associated with the bottom of the weathering zone. 

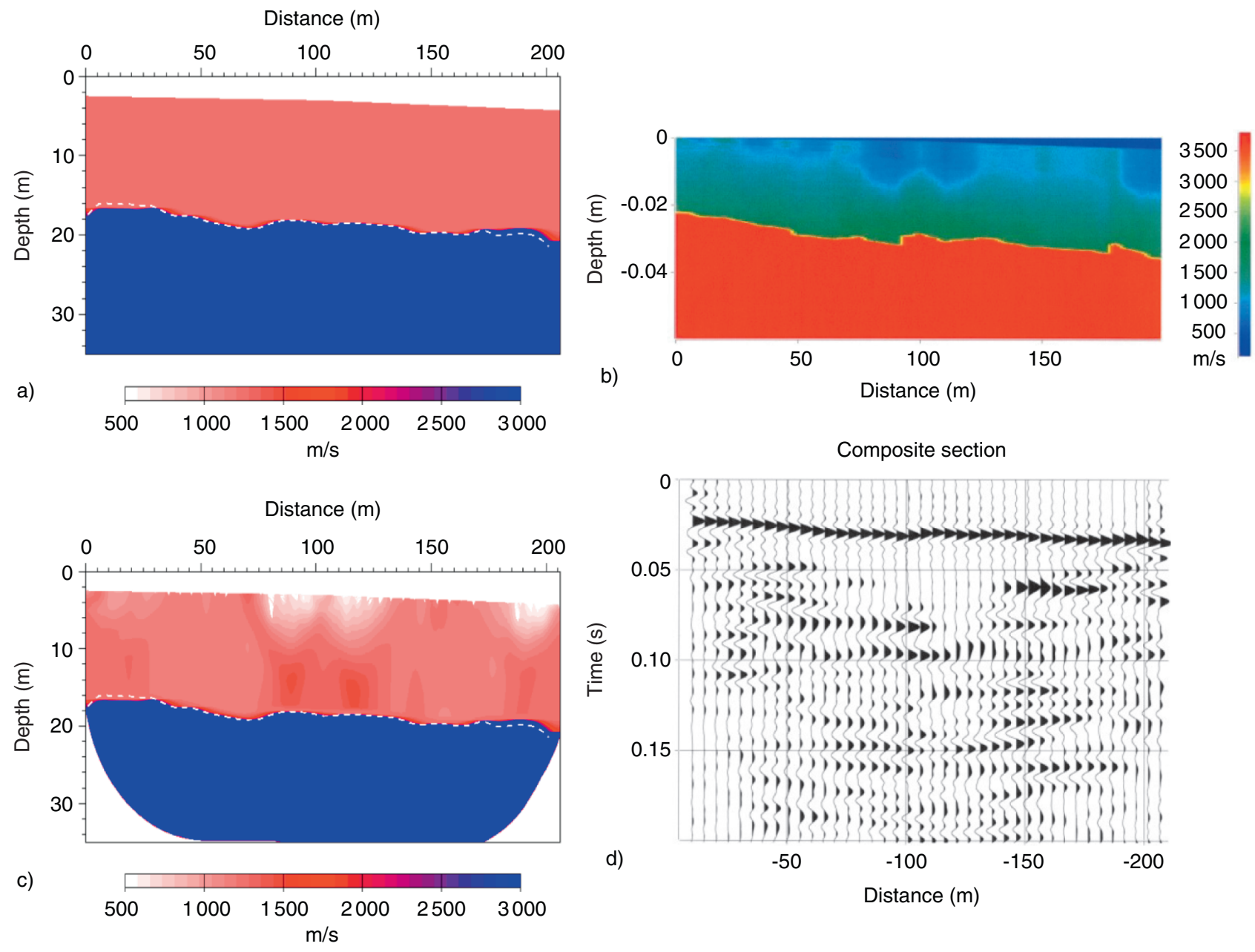

Figure 8

Third field example: reflectivity section for the 10EST06 profile. a) Velocity model provided by the Plus-Minus method $(V 1=1205 \mathrm{~m} / \mathrm{s}$ and $V 2=4275 \mathrm{~m} / \mathrm{s}$ ). b) Velocity model from tomographic inversion after conversion depth to time. c) Velocity model provided by tomographic inversion. d) Composite section.

\section{IMAGING PROCEDURE: OTHER FIELD EXAMPLES}

The same three-step procedure to image reflectivity from the acquisition surface was successfully applied on several refraction profiles. Figures 7 and 8 display two other field examples coming from the same survey area.

The example presented in Figure 7, profile 10EST09, shows several stages of the procedure. The input velocity model derived from the Plus-Minus method is a single layer with a constant velocity $(V 1=1087 \mathrm{~m} / \mathrm{s})$ over a bedrock with a velocity of $V 2=3975 \mathrm{~m} / \mathrm{s}$ (Fig. 7a). The velocity model derived by tomographic inversion, after 16 iterations $(R M S=0.1 \mathrm{~ms})$, is shown in Figure 7c. The tomographic inversion results for the 10EST06 profile are shown in Figure 8a, c. The input velocity model defined as follows: $V 1=1205 \mathrm{~m} / \mathrm{s}$, $V 2=4275 \mathrm{~m} / \mathrm{s}$. After inversion, the $R M S$ error is $0.06 \mathrm{~ms}$. A comparison between the initial and the final model shows lateral variations of velocity in the weathering zone, which is a heterogeneous shaly mudstone over a compacted limestone.

The associated composite sections are shown in Figures $7 \mathrm{~d}$ and $8 \mathrm{~d}$. The reflections between 20 and $30 \mathrm{~ms}$ are associated with the top of the bedrock, which is a compacted limestone.

\section{CONCLUSION}

This study indicates that in addition to delineating seismic velocity interfaces, the information contained in 
refraction survey data can provide images of reflectivity for the near and very near surface in engineering and environmental geophysics.

We have demonstrated that the hybrid inversion scheme for processing first arrivals provides reliable velocity models beyond what can be produced using conventional seismic refraction methods. Apart from this, the shot points recorded for the refraction survey can be processed in order to obtain high resolution single-fold seismic sections, provided that sufficient attention is given the estimation of statics corrections, velocity models and noise attenuation. We have also shown how the velocity model obtained by refraction tomography can be used to compute a reflectivity model for the very near surface. When merged with the conventional reflectivity section obtained from the highresolution reflection profile, a composite section is formed that extends the reflectivity image to the acquisition surface and enhances near-surface characterization.

The field data examples illustrate the potential in merging 2 innovative sections, extracted from different parts of the seismic wave field, that enable us to resolve reflectivity and image from the ultra-shallow surface to deeper structures with a simple processing of seismic data acquired in a fast and inexpensive manner for refraction seismic surveying, without increased acquisition costs.

\section{ACKNOWLEDGMENTS}

We thank Matthew Ralston and Daniel Guillemot for their valuable help and advices that significantly improved the manuscript. The authors also thank Andra for permission to use the data presented in the field examples.

\section{REFERENCES}

Cerveny V., Soares J.E.P. (1992) Fresnel volume ray-tracing, Geophys. 57, 902-915.

Hagedoorn G.J. (1959) The Plus-Minus method of interpreting seismic refraction sections, Geophys. Prospect. 7, 158-182.
Mari J.L., Delay F. (2011) Contribution of seismic and acoustic methods to reservoir model building, Chapter 17 in Hydraulic Conductivity - Issues, Determination and Applications, Book 1, InTech-Open Access Publisher.

Mari J.L., Glangeaud F., Coppens F. (1999) Signal processing for geologists and geophysicists, Editions Technip, Paris.

Mari J.L., Mendes M. (2012) High resolution 3D near surface imaging of fracture corridors and cavities by combining Plus-Minus method and refraction tomography, Near Surface Geophys. 10, 185-195.

Mendes M. (2009) A hybrid fast algorithm for first arrivals tomography, Geophys. Prospect. 57, 803-809.

Nayan K.A.M., Rafek A.G., Ismail A., Taha M.R., Rosyidi S.A.P. (2003) An Integration of the Seismic Methods in Characterization of An Unsaturated Granitic Residual Soil Site, Proc. of The 2nd Asian Conference on Saturated Soils, Osaka, Japan, 15-17 April, pp. 85-90.

Palmer D. (1986) Refraction Seismic: the lateral resolution of structure and seismic velocity, Geophysical Press, London.

Podvin P., Lecomte I. (1991) Finite difference computation of travel times in very contrasted velocity models: massively parallel approach and its associated tools, Geophys. J. Int. 105, 271-284.

Redpath B.B. (1973) Seismic refraction exploration for engineering site investigations, Explosive Excavation Research Laboratory Livermore, California.

Sain K., Kaila K.L. (1996) Interpretation of first arrival travel times in seismic refraction work, Pageoph 147, 181-194.

Whiteley R.J., Eccleston P.J. (2006) Comparison of shallow seismic refraction interpretation methods for regolith mapping, Explor. Geophys. 37, 340-347.

Wongpornchai P., Phatchaiyo R., Srikoch N. (2009) Seismic Refraction Tomography of Mae-Hia Landfill Sites, Mueang District, Chiang Mai, World Acad. Sci. Eng. Technol. 56, 678-681.

Yilmaz O. (1987) Seismic data processing, Society of Exploration Geophysicist, Tulsa.

Zelt C.A., Azara A., Levander A. (2006) 3D seismic refraction traveltime tomography at a groundwater contamination site, Geophys. 71, H67-H78.
Manuscript accepted in December 2012 Published online in August 2013 